Clemson University

TigerPrints

$12-2019$

\title{
Comparison Study of Mold Growth Resistance of Plastic Based Material Flooring (PBM Flooring) and Ceramic Tile Flooring
}

Jyothi Rangineni

Tile Council of North America

Jeremy Tzeng

Clemson University, tzuenrt@clemson.edu

Follow this and additional works at: https://tigerprints.clemson.edu/bio_pubs

Part of the Biochemistry, Biophysics, and Structural Biology Commons, and the Materials Science and Engineering Commons

\section{Recommended Citation}

Rangineni, Jyothi and Tzeng, Jeremy, "Comparison Study of Mold Growth Resistance of Plastic Based Material Flooring (PBM Flooring) and Ceramic Tile Flooring" (2019). Publications. 113.

https://tigerprints.clemson.edu/bio_pubs/113

This Article is brought to you for free and open access by the Biological Sciences at TigerPrints. It has been accepted for inclusion in Publications by an authorized administrator of TigerPrints. For more information, please contact kokeefe@clemson.edu. 


\title{
Clemson University \\ Department of Biological Sciences
}

\author{
Research Report | December 2019
}

\section{Comparison Study of Mold Growth Resistance of Plastic Based Material Flooring (PBM Flooring) and Ceramic Tile Flooring}

\section{Jyothi Rangineni, Ph.D.}

Research Scientist, Tile Council of North America

Jeremy Tzeng, Ph.D.

Associate Professor, Department of Biological Sciences, Clemson University Faculty Scholar, School of Health Research, Clemson University

Department of Biological Sciences

132 Long Hall, Clemson, SC 29634

Tel: 864-656-2328

www.clemson.edu/science/departments/biosci/ 


\section{NOTICE OF DISCLAIMER AND LIMITATION OF LIABILITY}

This report was prepared in collaboration with Dr. Tzeng in the Department of Biological Sciences at Clemson University and the Tile Council of North America Product Performance Testing Laboratory and is protected by copyright law. It reflects a summary of research in progress, which continues to evolve, and is intended to apply only as to product specimens actually reviewed and tested. Results may not necessarily apply or be extrapolated to items that were not tested. The report may refer to information from third parties, which is beyond the control of the authors. The report is not an endorsement, recommendation, approval, certification, or criticism of any particular product, method, or application, and it is offered "as is" without warranty of any kind. 


\section{Table of Contents}

1.0 Executive Summary ........................................................................................................................... 5

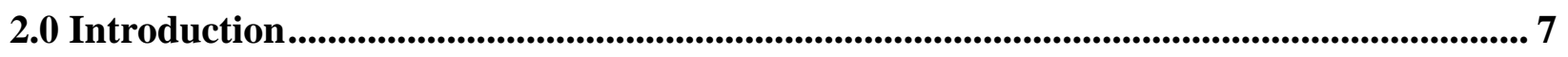

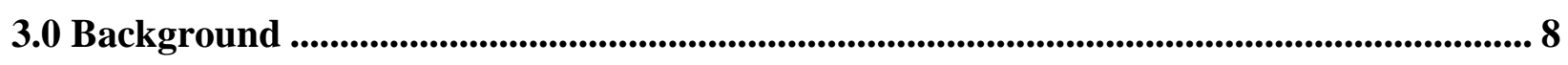

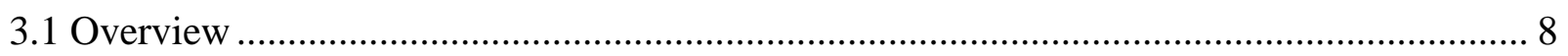

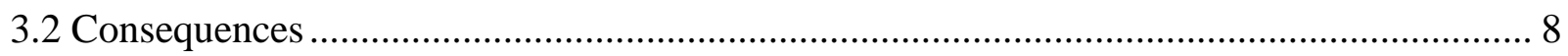

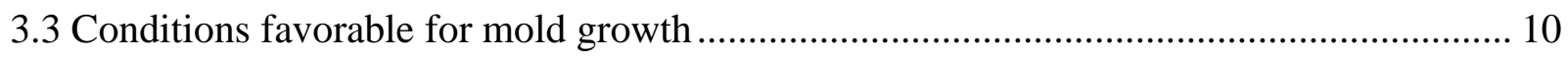

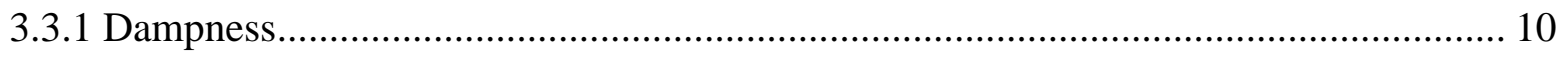

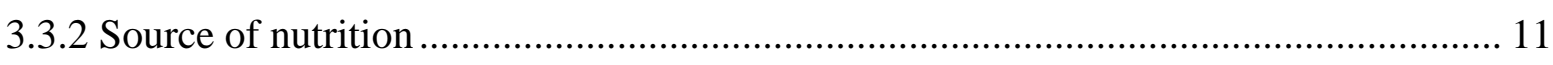

3.3.3 Effect of moisture and temperature on mold growth............................................... 11

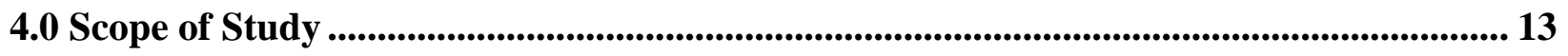

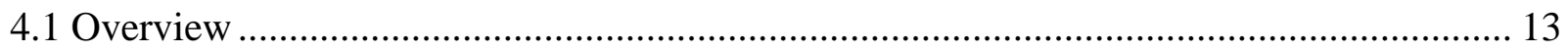

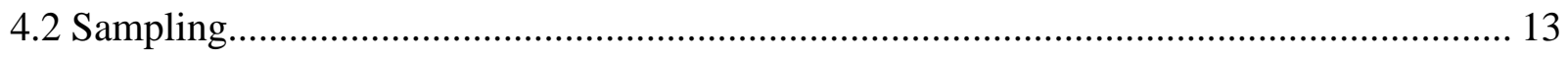

4.2.1 Definition of PBM floor coverings................................................................... 13

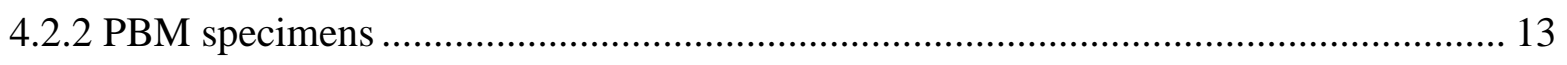

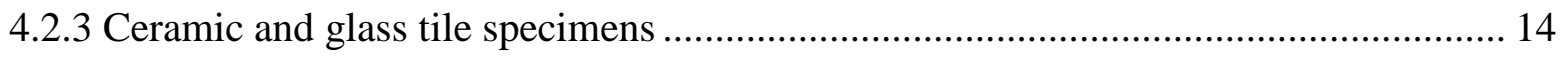

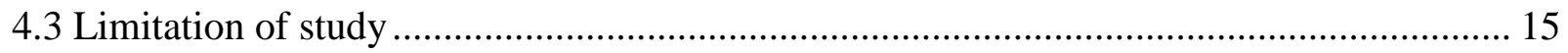

5.0 Evaluation of Mold Growth .................................................................................................. 16

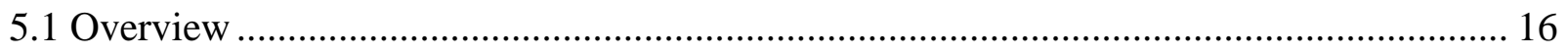

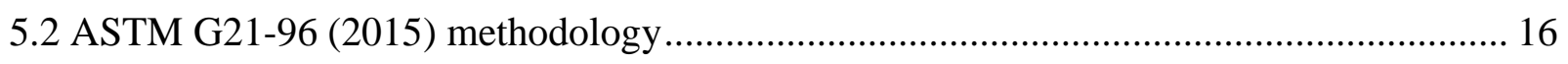

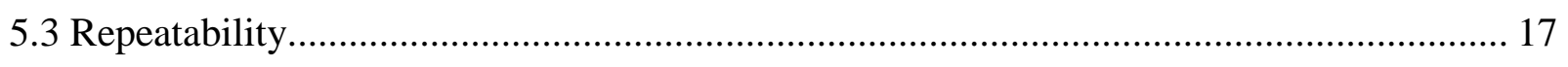

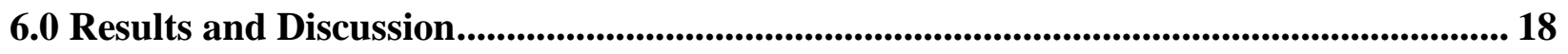

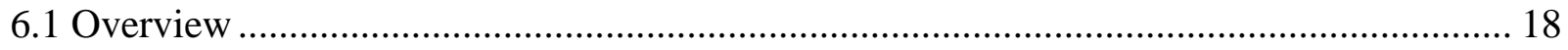

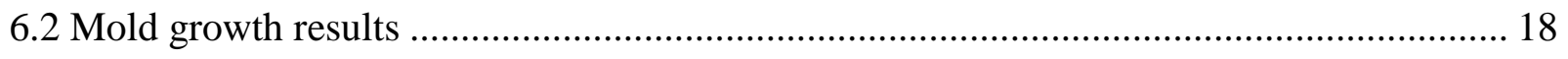

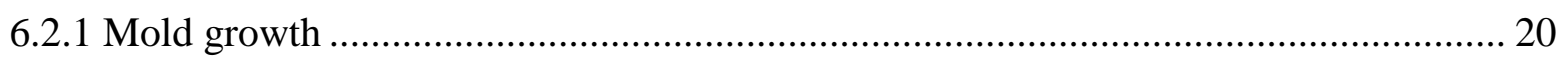

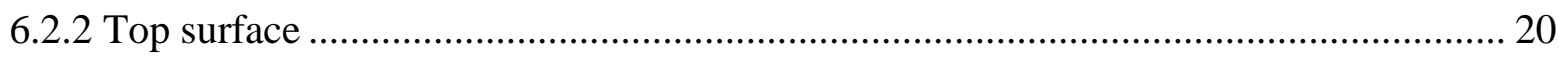

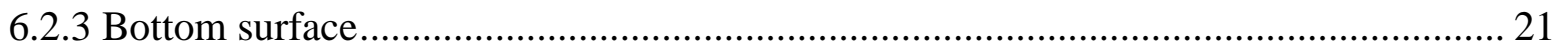

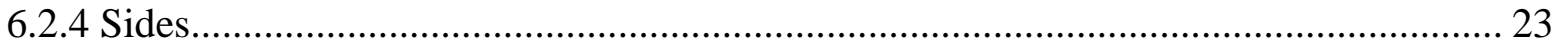

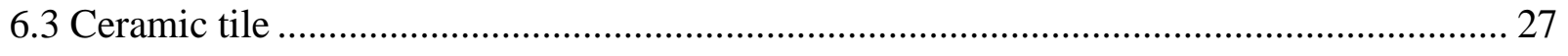

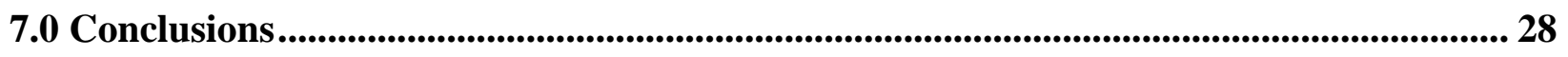




\section{Table of Contents (Continued)}

\section{List of Tables}

5.2.1 Mold index according to ASTM G-21 ........................................ 17

6.2.1 Summary of evaluation of mold growth on PBM flooring specimens....................19

\section{List of Figures}

3.3.3.1: Isopleths of mold germination and growth rate. Germination time in days (d) and growth

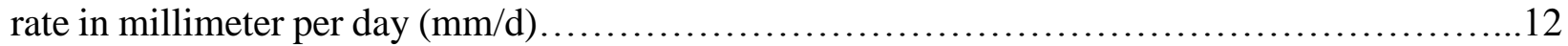

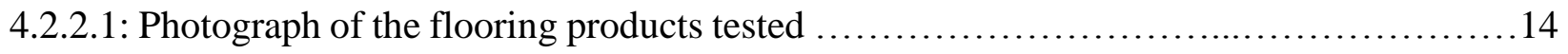

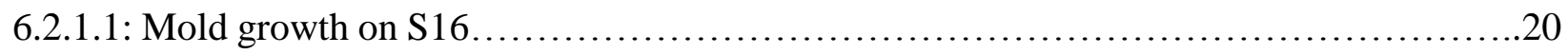

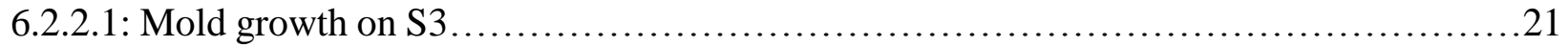

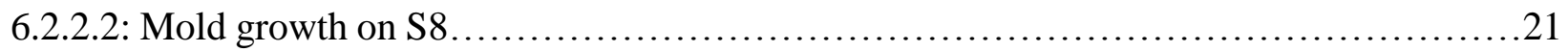

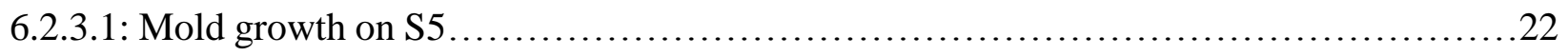

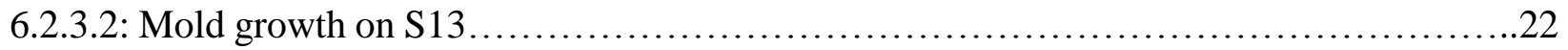

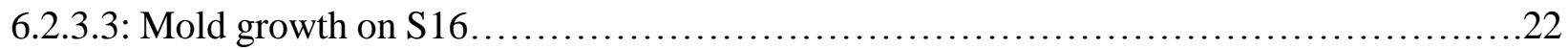

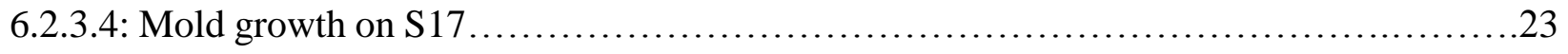

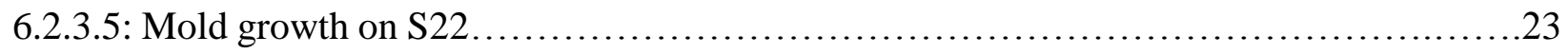

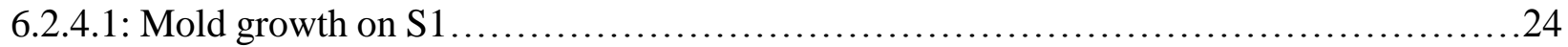

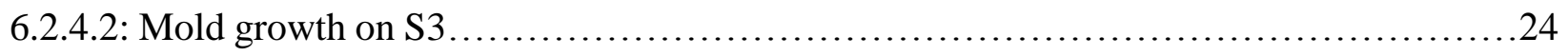

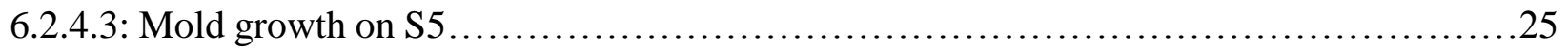

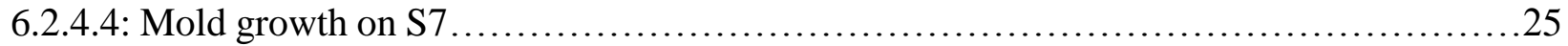

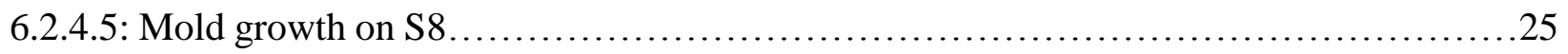

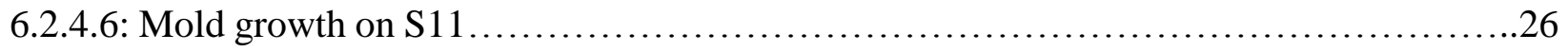

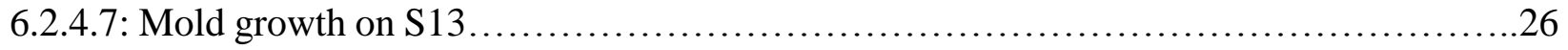

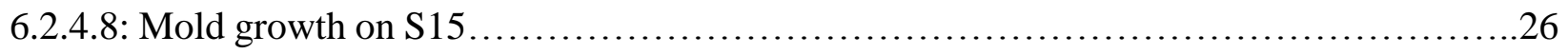

6.3.1: Mold growth on ceramic tile (porcelain) - top and bottom surfaces.....................27 


\subsection{Executive Summary}

Clemson University Department of Biological Sciences and Tile Council of North America Product Performance Testing Laboratory evaluated whether ceramic tile and Plastic Based Material $\left(\mathrm{PBM}^{1}\right)$ flooring support mold growth when exposed to fungal spores.

Mold grows in moisture-rich environments and requires only minimal sources of nutrition to support growth. It has long been identified to cause damage to buildings and construction materials and its presence in buildings has been connected to many major health concerns with various studies and reviews published on this matter. ${ }^{2}$

The method used to evaluate mold growth was ASTM G21-96 (2015). ${ }^{3}$ This test method is robust and is performed with minimal salts media and no nutrients. The test fungi have to utilize any carbon sources present in test specimens to support their growth. As the test setup provides no nutrients for the mold to grow, any growth is attributed to nutrients in the test specimen that support mold growth.

Testing was conducted on $25 \mathrm{PBM}$ products that manufacturers ${ }^{4}$ advertise or claim to be waterproof, water resistant, or depict being used in areas where flooring gets wet. ${ }^{5}$ For 22 out of 25 products $(88 \%)$, the manufacturers also disclaimed damage from mold or excessive moisture in the product warranties. ${ }^{6}$ The results of this study, including a total of three repetitions of all testing, show that $100 \%$ of the PBM products tested supported mold growth. The growth of fungi was observed on all surfaces on some PBM products and only on certain surfaces (top, bottom, or sides) on others. Such mold growth can release spores, mycotoxins, microbiological volatile

\footnotetext{
${ }^{1}$ PBM flooring described herein includes, but is not limited to, flooring products recognized in the marketplace as Resilient Floor Coverings, Luxury Vinyl Tile (LVT), Luxury Vinyl Plank (LVP), Wood Polymer Composite (WPC), Stone Polymer Composite (SPC), Clay Polymer Composite (CPC), and Rigid Core Board (RCB).

${ }^{2}$ Dyląg, Mariusz. Fungi present in home and their impact on human health-A short. Biol Med 1 (2017): 016-025.

${ }^{3}$ ASTM G21-96 (2015) Standard Practice for Determining Resistance of Synthetic Polymeric Materials to Fungi.

4 "Manufacturer" in the context of this report refers to any of the following: actual manufacturer, apparent manufacturer, or primary importer.

${ }^{5}$ Claims of being waterproof or water resistant or depicted being used in areas where flooring gets wet were found by the authors in product literature or advertisements and have been archived using an internet archive "Wayback Machine." https://web.archive.org/.

${ }^{6}$ Manufacturer warranties were examined for disclaimers regarding mold growth or problems due to excessive moisture for the products tested and have been archived.
} 
organic compounds (MVOC's) and other environmental toxicants to contaminate indoor air through a variety of mechanisms as detailed in Section 3.2. The ceramic tile tested did not support mold growth.

Given the possibility of material degradation and potentially serious health consequences from mold growth as detailed in Section 3.2, and the likelihood of damp and favorable conditions for mold growth as detailed in Section 3.3, a dry use-only caution, and/or warning regarding potential for mold growth, should be considered for products that perform similarly to those tested for this report. This is especially relevant given the exclusion for mold damage in many of the products' warranties. 


\subsection{Introduction}

This report describes an evaluation of PBM flooring and ceramic tile to support mold growth. Research was conducted on 25 PBM products collected from various sources and repeated a total of three times. These products were made by 16 PBM manufacturers. For comparison, representative specimens of ceramic tiles and glass were also included in the study.

The objectives of the study were (1) to determine whether PBM flooring supports mold growth, and (2) to compare mold growth on PBM flooring and ceramic tile to assess their relative performance. All analyses were conducted by the TCNA Product Performance Testing Laboratory.

In Section 3 of this report, a comprehensive background is provided, including reasons for the research. Section 4 and 5 detail the scope of study, sampling, and the research methodology. Results are discussed in Section 6 with a focus on the relevance of such and their potential health impact. In Section 7, conclusions are drawn from this research and information obtained from peer reviewed publications. 


\subsection{Background}

\subsection{Overview}

Detailed in this section is a review of the consequences of mold growth in buildings from various peer reviewed studies. Additionally, factors supporting the growth of mold, relevant especially to the materials evaluated in this study, are also discussed.

\subsection{Consequences}

Mold and fungus growth have long been identified to cause damage to buildings and construction materials. Mold growth can result in issues ranging from surface discoloration and odor to serious mechanical failures and health concerns. While visible mold growth is always concerning, nonvisible mold growth can be a larger concern as a hidden cause for issues including structural damage, ${ }^{7}$ material degradation, ${ }^{8}$ and sickness. ${ }^{9}$

Various studies and reviews have been published on health effects due to mold in buildings ${ }^{10}$ with respiratory and allergic effects dominating the spectra of ailments. ${ }^{11}$ There have been many accounts of both minor and severe mold-induced health symptoms, including where researchers showed an epidemiologic association between pulmonary hemorrhaging in small children and water-damaged homes containing toxic fungi. ${ }^{12}$

These ailments in part occur because mold releases spores into the air as a means of reproduction. In addition, cellular debris, such as cell wall material, can be released into the building environment and is a known allergen. Because of their small size (including submicron fragments) mold spores

\footnotetext{
${ }^{7}$ TenWolde, A. Mold and decay in TriState homes. In Proceedings of the second annual conference on durability and disaster mitigation in wood-frame housing. Madison, WI: Forest Products Society. (2002): 53-57.

${ }^{8}$ Viitanen H, Vinha J, Salminen K, Ojanen T, Peuhkuri R, Paajanen L, et al. Moisture and bio-deterioration risk of building materials and structures. J Build Phys. 2010;33(3):201-224.

9 WHO. World Health Organization (WHO) Guidelines for Indoor Air Quality: Dampness and Mould, Bonn, Germany: WHO Regional Office for Europe; 2009. http://www.euro.who.int/document/E92645.pdf. Accessed January 15, 2016.

${ }^{10}$ Dyląg, Mariusz. Fungi present in home and their impact on human health-A short. Biol Med 1 (2017): 016-025.

${ }^{11}$ Mendell MJ, Mirer AG, Cheung K, Tong M, Douwes J. Respiratory and allergic health effects of dampness, mold, and dampness-related agents: a review of the epidemiologic evidence. Environ Health Perspect. (2011): 119(6):748756.

${ }^{12}$ Vesper S, Dearborn DG, Yike I, Allan T, Sobolewski J, Jinkley SF, et al. Evaluation of stachybotrys chartarum in the house of an infant with pulmonary hemorrhage: quantitative assessment before, during, and after remediation. $J$ Urban Health. (2000): 77(1):68-85.
} 
and cellular debris can be invisible to the naked eye and travel freely through tiny cracks and crevices in flooring, to enter indoor air. ${ }^{13,14}$

Studies have also shown that spores can be pushed into indoor air from sub-flooring layers by dayto-day activities, such as walking. ${ }^{15}$ This simple action can result in spores contaminating indoor living spaces and potentially growing upon other building materials that are good sources of nutrition in environments with high humidity (for example, wallpaper in the bathroom, nearby carpeted areas, and furniture). The health problems caused by these mold allergens can vary widely, differing from person to person, so occupants of a building with similar mold growth may report very different reactions.

Growth of fungi can also result in the release of environmental toxicants such as microbiological volatile organic compounds (MVOCs), which have been linked to sick building syndrome. ${ }^{16,17}$ These are organic compounds in a gaseous state that through gaseous diffusion will spread throughout a building. Additionally, enzymes produced by mold are capable of totally or partially breaking the ester linkages present in plasticizers (such as those used in PBM products) into more volatile components, which can then be released as VOC emissions into indoor air. ${ }^{18}$ Another study reported that emission of a dialkyl phthalate plasticizer is accelerated by the presence of mold growth. ${ }^{19}$ Further, plasticizers themselves have been reported to increase the adhesion of certain deteriogenic mold to PVC, leading to biodegradation of the $\mathrm{PVC}^{20}$

\footnotetext{
${ }^{13}$ Matilainen, M., and P. Pasanen. Transport of fungal spores from crawl space to indoors. Proceedings of 9th International Conference on Indoor Air Quality and Climate, Monterey, California, June, pp. 736-741. 2002.

${ }^{14}$ Airaksinen, M., J. Kurnitski, P. Pasanen, and O. Seppanen. Fungal spore transport through a building structure. Indoor air 14, no. 2 (2004): 92-104.

${ }^{15}$ Buttner, M. P., Cruz-Perez, P., Stetzenbach, L. D., Garrett, P. J., \& Luedtke, A. E. Measurement of airborne fungal spore dispersal from three types of flooring materials. Aerobiologia (2002) 18(1), 1-11.

${ }_{16}$ Mølhave L Volatile organic compounds and the sick building syndrome. In: Lippmann M (ed) Environmental toxicants: human exposures and their health effects, 3rd edn. Wiley-Interscience, New York. (2009): $241-256$.

${ }^{17}$ Straus DC Molds, mycotoxins, and sick building syndrome. Toxicol Ind Health. (2002)25:617-635.

${ }^{18}$ El-Aghoury, A., R. K. Vasudeva, D. Banu, M. Elektorowicz, and D. Feldman. Contribution to the study of fungal attack on some plasticized vinyl formulations. Journal of Polymers and the Environment 14, no. 2 (2006): 135.

${ }^{19}$ Gumargalieva, K. Z., G. E. Zaikov, S. A. Semenov, and O. A. Zhdanova. The influence of biodegradation on the loss of a plasticiser from poly (vinyl chloride). Polymer degradation and stability 63, no. 1 (1999): $111-112$.

${ }^{20}$ Webb JS, Vander Mei HC, Nixon M, Eastwood IM, Greenhalagh IM, Read SJ, Robson D, Handley PS (1999) Appl Environ Microbiol. (1999) 65:3575.
} 
In addition to MVOCs, some molds, under certain circumstances, produce mycotoxins, which can be serious allergens potentially causing respiratory diseases. ${ }^{21}$ In general, these compounds consist of large organic molecules that do not diffuse through the air in the same manner as MVOCs but rather are present in contaminated dust, debris or spores. Exposure to these toxins is most likely when areas with mold growth are disturbed.

\subsection{Conditions favorable for mold growth}

\subsubsection{Dampness}

Moisture that collects within the flooring, and layers beneath, presents a favorable environment for mold and fungi to grow. Moisture accumulation in indoor environments can stem from many sources, such as moisture transfer from outdoors, groundwater intrusion, and condensation in cold climates. ${ }^{22}$ Various studies have shown that regular indoor activities such as cooking, showering, and cleaning, ${ }^{23}$ and sporadic maintenance issues such as plumbing leaks, ${ }^{24}$ also can contribute to moisture accumulation with such moisture being absorbed into walls and subflooring. ${ }^{25,26}$ In addition to moisture from routine indoor activities, direct exposure to moisture may further create damp conditions supporting the growth of mold.

PBM flooring products claiming to be $100 \%$ waterproof were recently tested by the Tile Council of North America Product Performance Testing Laboratory and the Bishop Materials Laboratory

\footnotetext{
${ }^{21}$ Heutte, N., André, V., Arvis, C. D., Bouchart, V., Lemarié, F., Legendre, P. \& Gente, S. Assessment of multicontaminant exposure in a cancer treatment center: a 2-year monitoring of molds, mycotoxins, endotoxins, and glucans in bioaerosols. Environmental monitoring and assessment. (2017)189(1): 31.

22 Harriman LG, Lstiburek J, Kittler R. Improving humidity control for commercial buildings. ASHRAE J. (2000):42(63):24-30.

${ }^{23}$ Oreszczyn T, Pretlove SEC. Condensation Targeter II. Modelling surface relative humidity to predict mould growth in dwellings. CIBSE A Build Serv Eng Res Technol. (1999):20(3):143-153.

${ }^{24}$ Glass SV, TenWolde A. Review of moisture balance models for residential indoor humidity. Montreal, Quebec: Proceedings from the 12th Canadian Conference on Building Science and Technology: (2009).

${ }^{25}$ Rode, Carsten, Ruut Hannele Peuhkuri, Lone Hedegaard Mortensen, Kurt Kielsgaard Hansen, Berit Time, Arild Gustavsen, Tuomo Ojanen et al. Moisture buffering of building materials. (2005).

${ }^{26}$ Glass, Samuel V., and Anton TenWolde. "Review of in-service moisture and temperature conditions in wood-frame buildings." General Technical Report FPL-GTR-174. Madison, WI: US Department of Agriculture, Forest Service, Forest Products Laboratory. (2003)53: 174.
} 
at Clemson University with all products allowing water to collect into and flow through the seams of the tested flooring materials. ${ }^{27}$

When testing in accordance to EN 13553 over a $0.15 \mathrm{~m}^{2}$ area, flow rates from $0.49 \mathrm{~L} / \mathrm{hr}$ to 7.54 $\mathrm{L} / \mathrm{hr}$ were measured. Water was observed to leak through the seams, exiting the edges, and through the seams appearing on the back of the floor covering, thus wetting all layers of the product.

\subsubsection{Source of nutrition}

Mold is a saprobe, which means that mold can survive on non-living organic matter. Mold adsorbs nutrients by breaking down hydrocarbons. It is commonly known that in the presence of moisture, mold will grow on any organic building material such as paper, adhesives, resins etc., unless a mold control compound (such as bleach) is also present. ${ }^{28,29,30}$

\subsubsection{Effect of moisture and temperature on mold growth}

It is widely reported that higher moisture levels and humidity promote the germination and growth of mold. Figure 3.3.3.1 provides growth rates and germination time as a function of relative humidity and temperature for Aspergillus sp. spores to germinate and grow. ${ }^{31}$

\footnotetext{
${ }^{27}$ Sanders, J, Spence, C, Standardized Waterproof Testing of Plastic Based Material Flooring (PBM Flooring), Bishop Materials Laboratory, Clemson University, November 2019.

${ }^{28}$ Spengler, John D., and Qingyan Chen. Indoor air quality factors in designing a healthy building. Annual Review of Energy and the Environment 25, no. 1 (2000): 567-600.

${ }^{29}$ Hoang, Chi P., Kerry A. Kinney, Richard L. Corsi, and Paul J. Szaniszlo. Resistance of green building materials to fungal growth. International Biodeterioration \& Biodegradation 64, no. 2 (2010): 104-113.

${ }^{30}$ Gutarowska, Beata. Metabolic activity of moulds as a factor of building materials biodegradation. Polish Journal of Microbiology 59, no. 2 (2010): 119-124.

${ }^{31}$ Smith, S. L.; Hill, S. T.: Influence of temperature and water activity on germination and growth of Aspergillus restrictus and Aspergillus versicolor. Transactions of the British Mycological Society Vol. 79 (1982), H. 3: 558 - 560.
} 


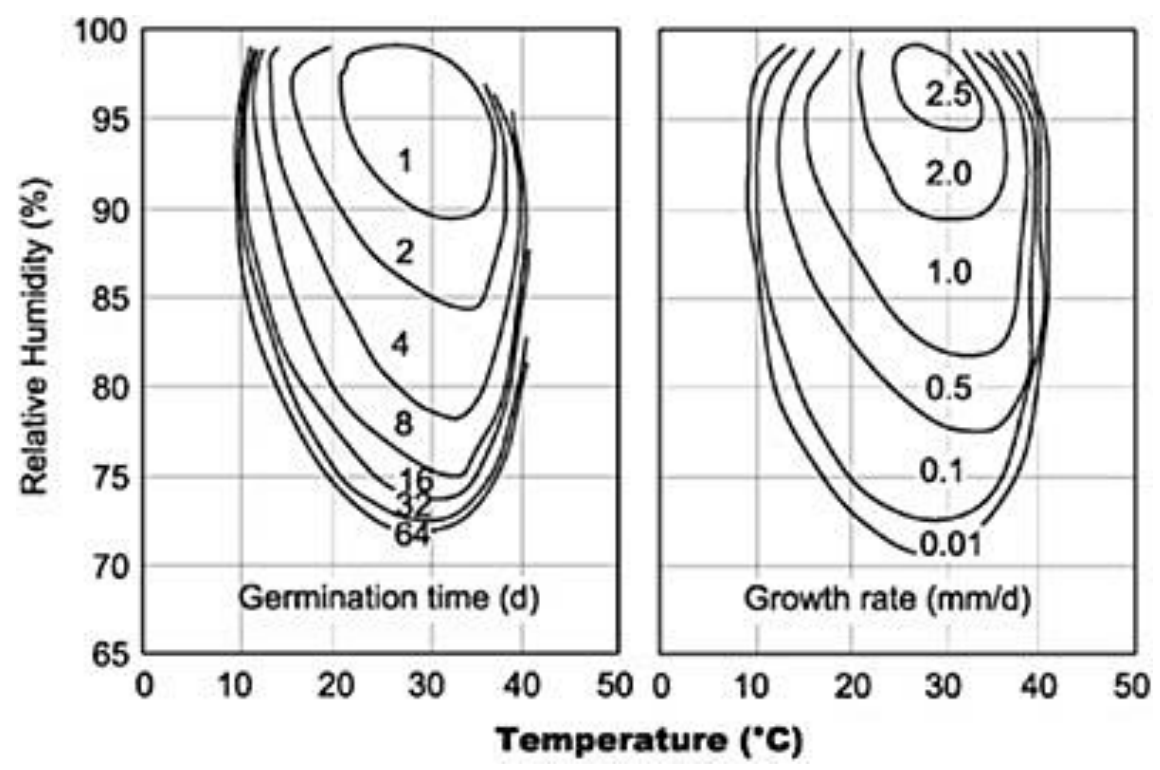

Figure 3.3.3.1: Isopleths of mold germination and growth rate. Germination time in days (d) and growth rate in millimeter per day $(\mathrm{mm} / \mathrm{d})$

Within limits, the more water that is present the faster mold will germinate and the faster it will grow. As can be seen in the isopleth, as dampness increases, the more quickly a mold problem can develop. From Figure 3.3.3.1, Aspergillus sp. spores will germinate on a material in conditions of $90 \%$ relative humidity and $30^{\circ} \mathrm{C}$ within a day. 


\subsection{Scope of Study}

\subsection{Overview}

In this section, the materials, methods and sampling employed in this evaluation are detailed.

\subsection{Sampling}

\subsubsection{Definition of PBM floor coverings}

PBM flooring described herein includes, but is not limited to, flooring products recognized in the marketplace as Resilient Floor Coverings, Luxury Vinyl Tiles (LVT), Luxury Vinyl Planks (LVP), Vinyl Composition Tiles (VCT), and tiles comprised from Wood Polymer Composites (WPC), Stone Polymer Composites (SPC), Clay Polymer Composites (CPC), and Rigid Core Boards (RCB).

The American Society for Testing and Materials (ASTM) F141-12 standard for resilient floor covering defines resilient flooring to be "an organic floor surfacing material made in sheet or tile or formed in place as a seamless material of which the wearing surface is non-textile. The resilient floor covering classification by common usage includes, but is not limited to asphalt, cork, linoleum, rubber, vinyl, vinyl composition, and polymeric poured seamless floors. Resilient in this sense is used as a commonly accepted term, but does not necessarily define a physical property."

\subsubsection{PBM specimens}

For this study, 25 PBM flooring specimens, from 16 manufacturers were collected from October 2018 to March 2019 from retail locations in South Carolina. These products were purchased based on the following criteria: (1) the product was easily obtainable, ${ }^{32}(2)$ was popular among specialty flooring resellers, designers, and architects, ${ }^{33}$ or (3) reflected current or upcoming trends among floor coverings. ${ }^{34}$

\footnotetext{
${ }^{32}$ Products were available for local pickup in 14 days or less.

${ }^{33}$ Products were advertised as "best sellers" with online retailers or were recommended by local retailers specializing in flooring.

${ }^{34}$ Based on advertisements from online retailers, local retailers specializing in flooring, or observations from Surfaces Trade Show held in Las Vegas, Nevada 2019.
} 
In total, eight rigid core, five SPC, one WPC, two interlocking non-rigid, one vinyl and eight glue down products were evaluated. All the products were advertised or claimed to be waterproof, water resistant, or depicted being used in areas where flooring gets wet. ${ }^{35}$ Of these, 22 of 25 products excluded damage from mold or excessive moisture in their warranty statements. ${ }^{36}$

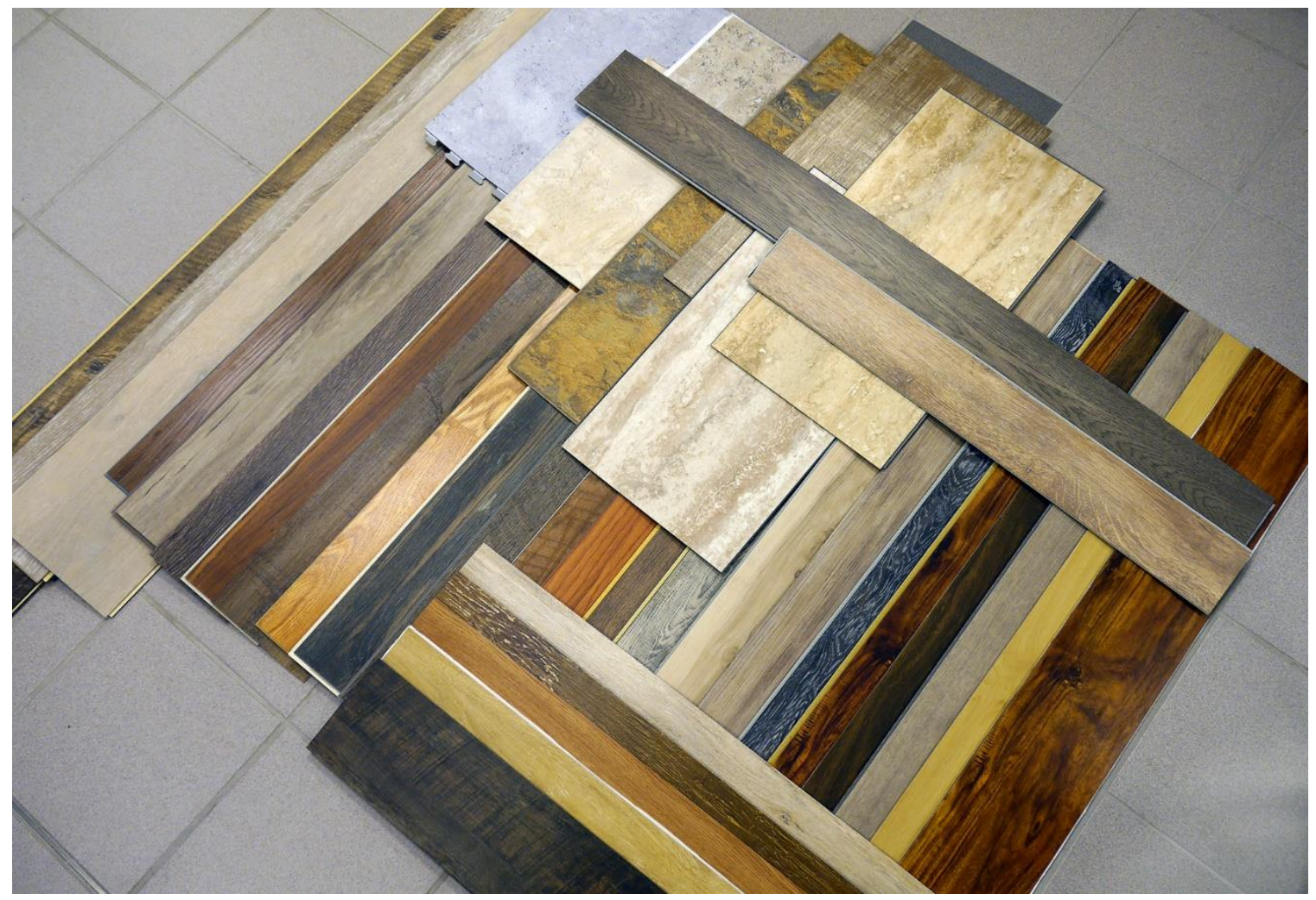

Figure 4.2.2.1: Photograph of the PBM flooring products tested

\subsubsection{Ceramic and glass tile specimens}

Also included in the study were representative specimens of ceramic tiles and glass. These included porcelain tiles, wall tiles, glass tiles with and without mesh backing and float glass.

\footnotetext{
${ }^{35}$ Claims of being waterproof, water resistant, or depicted being used in areas where flooring gets wet were found by the authors in product literature or advertisements and have been archived using an internet archive "Wayback Machine." https://web.archive.org/.

${ }^{36}$ Manufacturer warranties were examined for disclaimers regarding mold growth or problems due to excessive moisture for the products tested and have been archived.
} 


\subsection{Limitation of study}

Test results in this report only apply to the specimens tested. The results from these tests cannot necessarily be extrapolated to products currently in the marketplace. For further information, please refer to the disclaimer concerning this report located on page two. 


\subsection{Evaluation of Mold Growth}

\subsection{Overview}

Testing to evaluate mold growth was performed per the ASTM G21-96 (2015) standard test method. The procedure described in this standard consists of preparing specimens for testing, inoculation of the specimens with fungal spores, exposure of inoculated specimens under conditions favorable to growth, and examination and rating for visual growth.

\subsection{ASTM G21-96 (2015) methodology}

ASTM G21-96 (2015) ${ }^{37}$ was used to evaluate the capacity of fungi to grow on the flooring materials. Aspergillus niger (ATCC 9642), Gliocladium virens (ATCC 9645), Chaetomium globosum (ATCC 6205), Aureobasidium pullulans (ATCC 15233) and Penicillium pinophilum (ATCC 11797) were used as the inocula.

Minimal salts media were prepared and poured into $150 \mathrm{~mm}$ x $25 \mathrm{~mm}$ sterile petri plates. The salts agar has no nutrients to support mold growth.

The specimens were cut into $50 \mathrm{~mm}$ x $50 \mathrm{~mm}$ squares, sterilized with $70 \%$ ethyl alcohol and dried for 24 hours. All five molds were separately inoculated onto potato dextrose agar plates and incubated at $29 \pm 1{ }^{\circ} \mathrm{C}$ and relative humidity $\geq 85 \%$ until the entire surfaces of the petri plates were covered with fungal hyphae. Then, a spore suspension of each fungal inoculum was prepared by washing the culture surface of each fungus with $10 \mathrm{ml}$ of sterile water. The suspension was then transferred to respective sterile tubes containing sterile water. Tubes were shaken vigorously to separate the spores and break the spore clumps. A precipitate was obtained when the spore suspension was filtered and centrifuged. A final spore suspension was obtained by re-suspending the precipitate in sterile water. The concentration of the suspension was determined and adjusted to approximately $1 \times 10^{7}$ spores per $\mathrm{ml}$ using a counting chamber. Equal volumes of the resultant

\footnotetext{
${ }^{37}$ ASTM G21-96 (2015) Standard Practice for Determining Resistance of Synthetic Polymeric Materials to Fungi.
} 
spore suspensions were mixed together to obtain the final mixed spore suspension. This suspension was then transferred to a $50 \mathrm{ml}$ spray bottle and used as the source of fungal inoculum for testing.

Each specimen was placed in the center of a petri dish containing nutrients salts agar prepared as instructed in the test method, inoculated, and then incubated for 28 days at $29 \pm 1{ }^{\circ} \mathrm{C}$ and relative humidity $\geq 85 \%$. Specimens were examined and the growth rates determined using the mold index shown in Table 5.2.1. Growth observations were performed weekly.

A viability control was included for all tests to determine the viability of the fungal spores during the testing time. Whatman filter paper, which is a high source of carbohydrates, was used as the viability control. Also, a petri plate of minimal salts media was sprayed with fungal spores to confirm that the spores cannot germinate on it.

Table 5.2.1. Mold index according to ASTM G-21.

\begin{tabular}{|l|c|}
\hline Observed mold growth & Index (rating) \\
\hline No growth & 0 \\
\hline Traces of growth (less than 10\% coverage) & 1 \\
\hline Light growth (10-30\% coverage) & 2 \\
\hline Medium growth (30-60\%) & 3 \\
\hline Heavy growth (over 60\% coverage) & 4 \\
\hline
\end{tabular}

\subsection{Repeatability}

In each test run, the top and sides of three specimens and the bottom and sides of three specimens for each product were tested. This testing was repeated twice for a total of three test runs over four and a half months to allow an assessment of repeatability. In all tests, the results repeated exactly (i.e., no variation in the mold growth as evaluated according to the index rating in Table 5.2.1). 


\subsection{Results and Discussion}

\subsection{Overview}

The results of each test are detailed in this section. The severity and potential impacts of these results are also discussed.

\subsection{Mold growth results}

Table 6.2.1 presents the results from ASTM G21-96 (2015) testing. The extent of growth was judged by visual examination with the test specimens sorted into different categories in accordance with instructions in the standard procedure. Surfaces that were completely free from growth were given a rating of 0 (zero). Specimens with a rating of 1 showed weak traces of growth $(<10 \%$ coverage), while specimens with a rating 2-4 showed clear evidence of growth (10-90\% coverage). The ceramic tile specimens showed no growth. 
Table 6.2.1: Summary of evaluation of mold growth on PBM flooring specimens

\begin{tabular}{|c|c|c|c|}
\hline \multirow{2}{*}{$\begin{array}{c}\text { Specimen } \\
\text { ID }\end{array}$} & \multicolumn{3}{|c|}{ Mold Index } \\
\hline & Top surface & Bottom surface & Sides \\
\hline S1 & 0 & 0 & 3 \\
\hline $\mathrm{S} 2$ & 1 & 3 & 0 \\
\hline S3 & 3 & 0 & 3 \\
\hline S4 & 0 & 0 & 1 \\
\hline S5 & 0 & 3 & 3 \\
\hline S6 & 0 & 0 & 1 \\
\hline S7 & 0 & 2 & 3 \\
\hline S8 & 1 (edge) & 3 & 4 \\
\hline S9 & 0 & 1 & 2 \\
\hline S10 & 0 & 0 & 1 \\
\hline S11 & 0 & 0 & 3 \\
\hline S12 & 1 (edge) & 0 & 3 \\
\hline S13 & 1 (edge) & 3 & 3 \\
\hline S14 & 0 & 0 & 2 \\
\hline S15 & 0 & 0 & 4 \\
\hline S16 & 0 & 3 & 3 \\
\hline S17 & 0 & 3 & 2 \\
\hline S18 & 1 (edge) & 2 & 2 \\
\hline S19 & 0 & 2 & 2 \\
\hline S20 & 0 & 1 & 1 \\
\hline S21 & 0 & 1 & 2 \\
\hline S22 & 0 & 3 & 2 \\
\hline S23 & 3 & 4 & 4 \\
\hline S24 & 2 & 3 & 3 \\
\hline S25 & 1 & 1 & 0 \\
\hline
\end{tabular}




\subsubsection{Mold growth}

Mold was observed in various stages of growth and the specimens exhibited a wide range of germination times. Some specimens showed germination within a day with profuse growth in a week, while some specimens did not start showing mold growth until the last week of incubation. Well-developed sporulation was observed on all of the specimens, with those that exhibited early germination showing the highest sporulation. In some specimens, growth fibers could be clearly seen from the specimens to the agar. A typical example is shown in Figure 6.2.1.1.
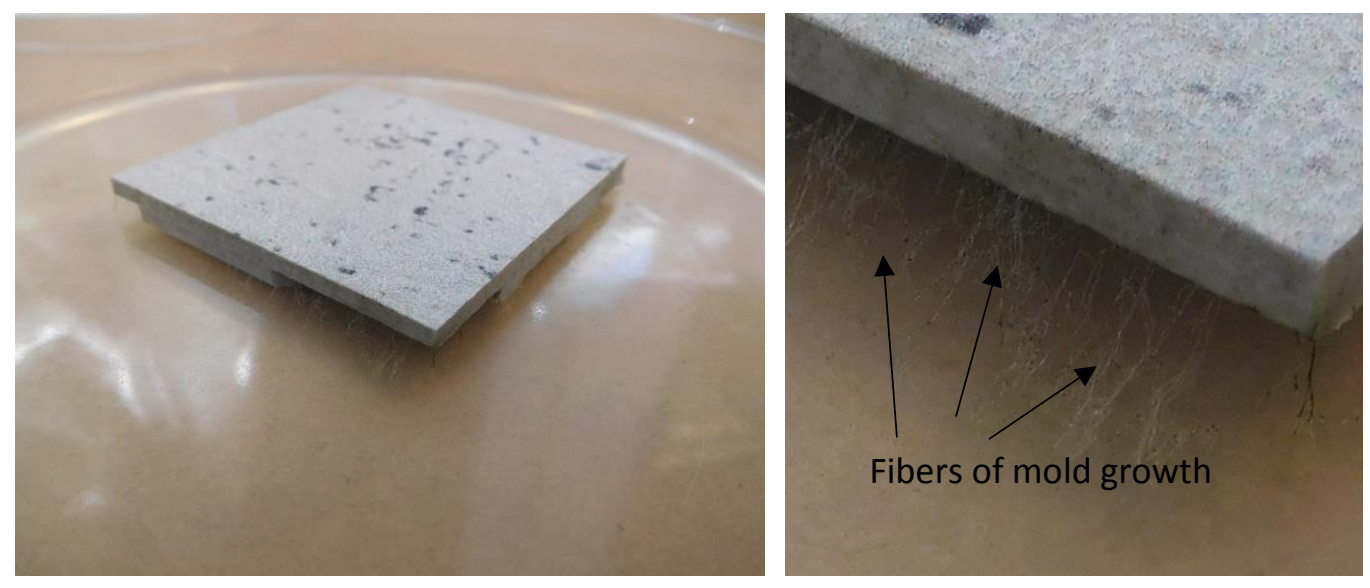

Figure 6.2.1.1: Mold growth on S16

The results are discussed in the following sections based on the surface upon which the growth was seen.

\subsubsection{Top surface}

Of the 25 PBM products tested, 9 of the specimens exhibited growth on the top surface. The growth was not profuse and not spreading; it was mostly focused and dotted on the edges and isolated throughout the surface. Growth on the top surface is generally not a major concern as regular cleaning inhibits the colonization and spread of mold. Growth on the top surface is only a problem when regular cleaning is absent, which can lead to the mold spreading, causing odor, discoloration, and release of spores. This could occur in areas that are hard to reach, such as flooring beneath refrigerators, behind washer/dryer units, etc. 

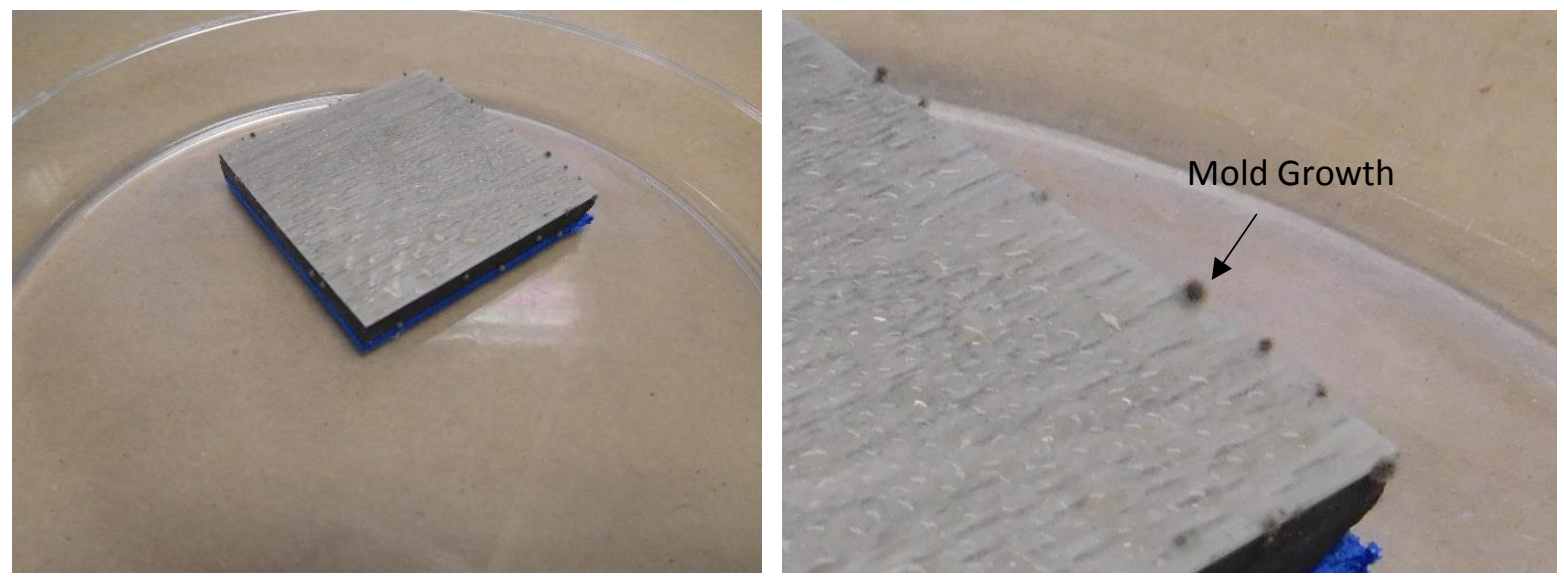

Figure 6.2.2.1: Mold growth on S3
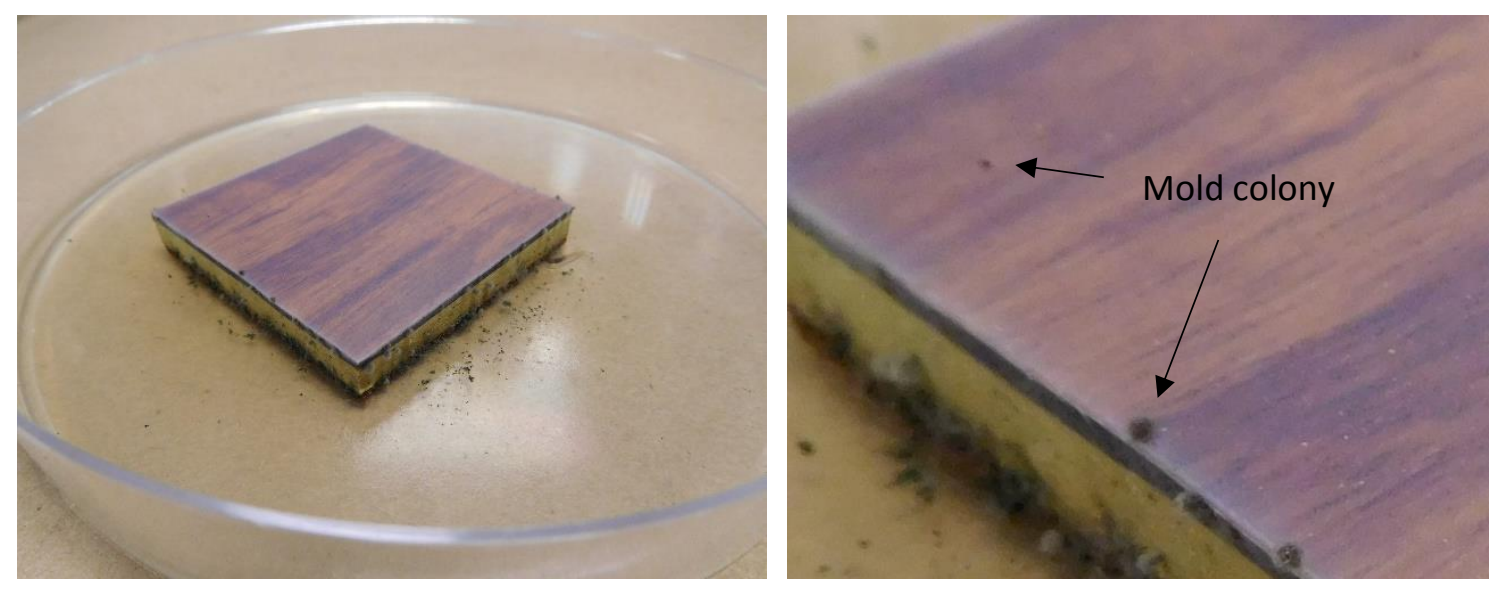

Figure 6.2.2.2: Mold growth on S8

\subsubsection{Bottom surface}

Figures 6.2.3.1 - 6.2.3.5 are examples of specimens exhibiting mold growth on the bottom surface. Sixteen of the 25 PBM flooring products exhibited such mold growth. The growth ranged from 13 per the ASTM G21-96 (2015) rating scale. It was observed that the extent of growth depended on the type of bottom layer, with profuse growth observed on products that had a cork, or corklike, bottom layer. Although mold on the bottom would be hidden under the flooring, spores and cellular debris from such mold can be transported to indoor air from day to day activities, such as walking on the floor as discussed in Section 3.2. Mold hidden in this fashion can be especially problematic during remediation projects due to the potential for a sudden release of potentially a large number of mold spores. 

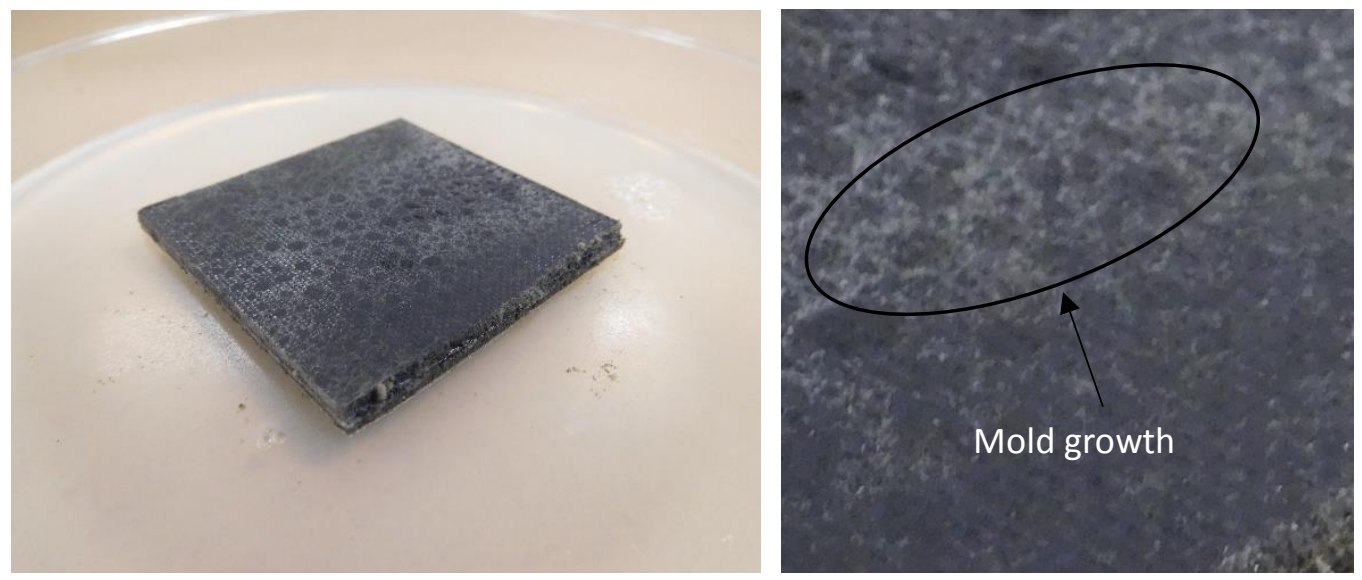

Figure 6.2.3.1: Mold growth on S5
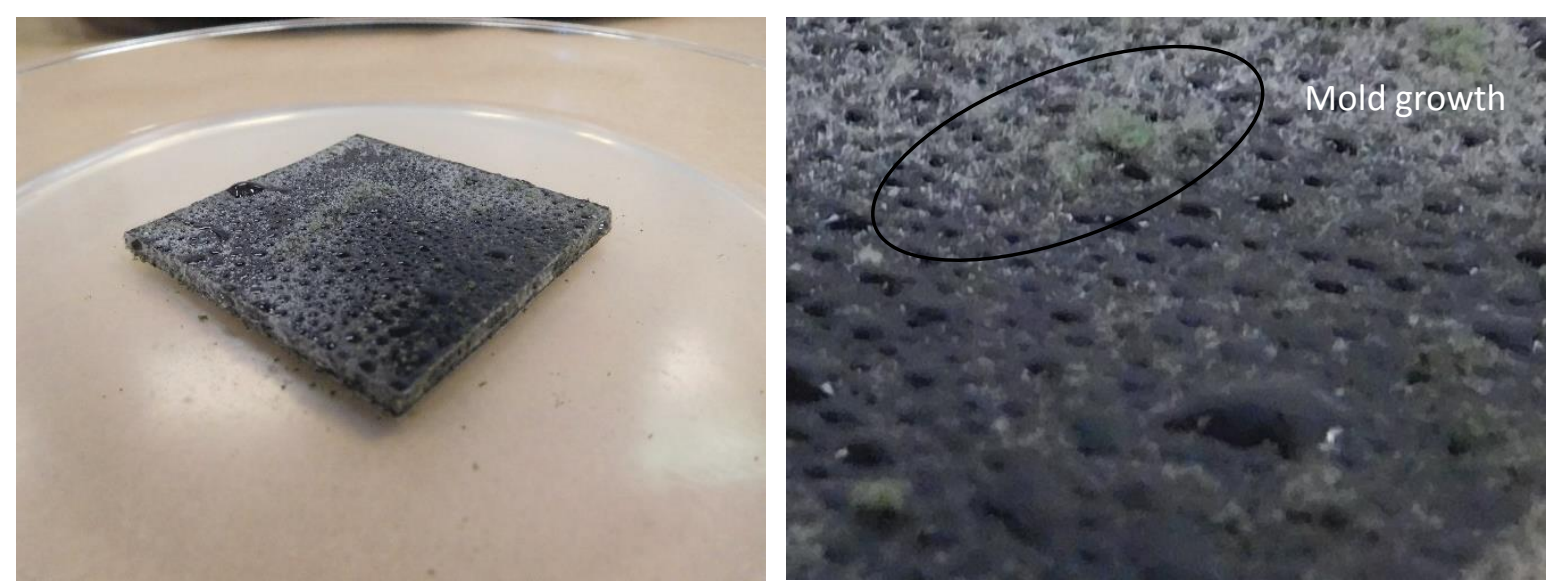

Figure 6.2.3.2: Mold growth on S13
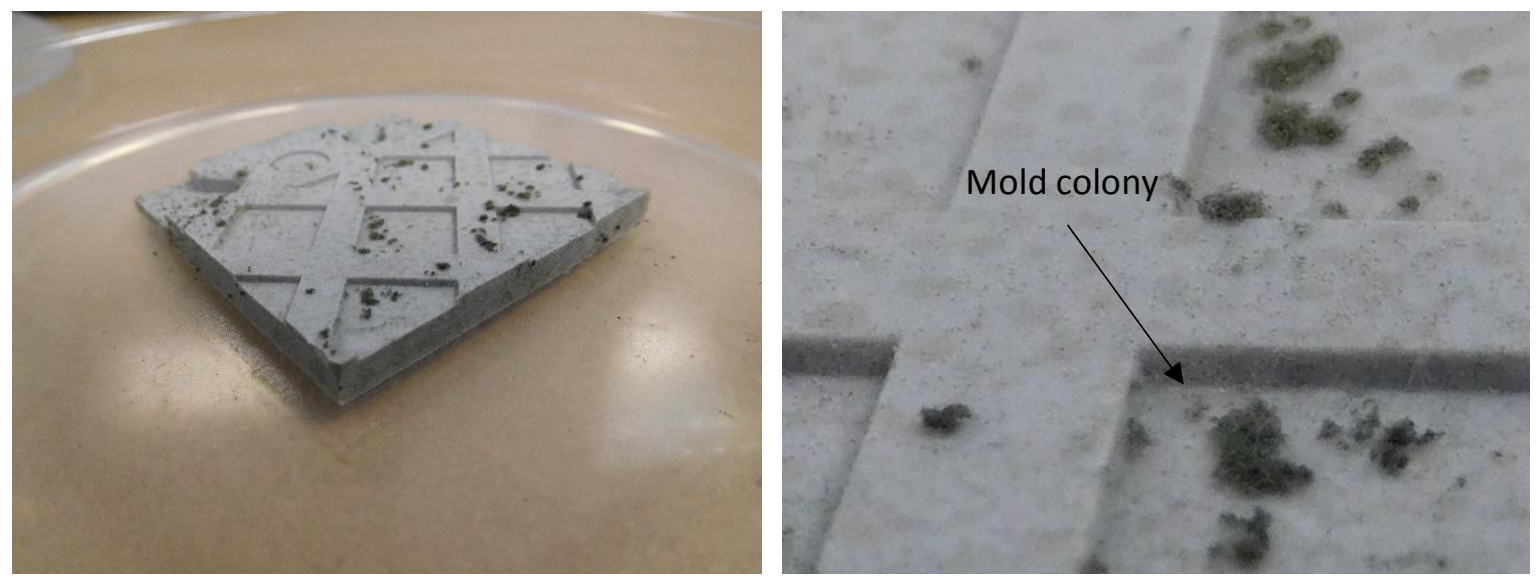

Figure 6.2.3.3: Mold growth on S16 

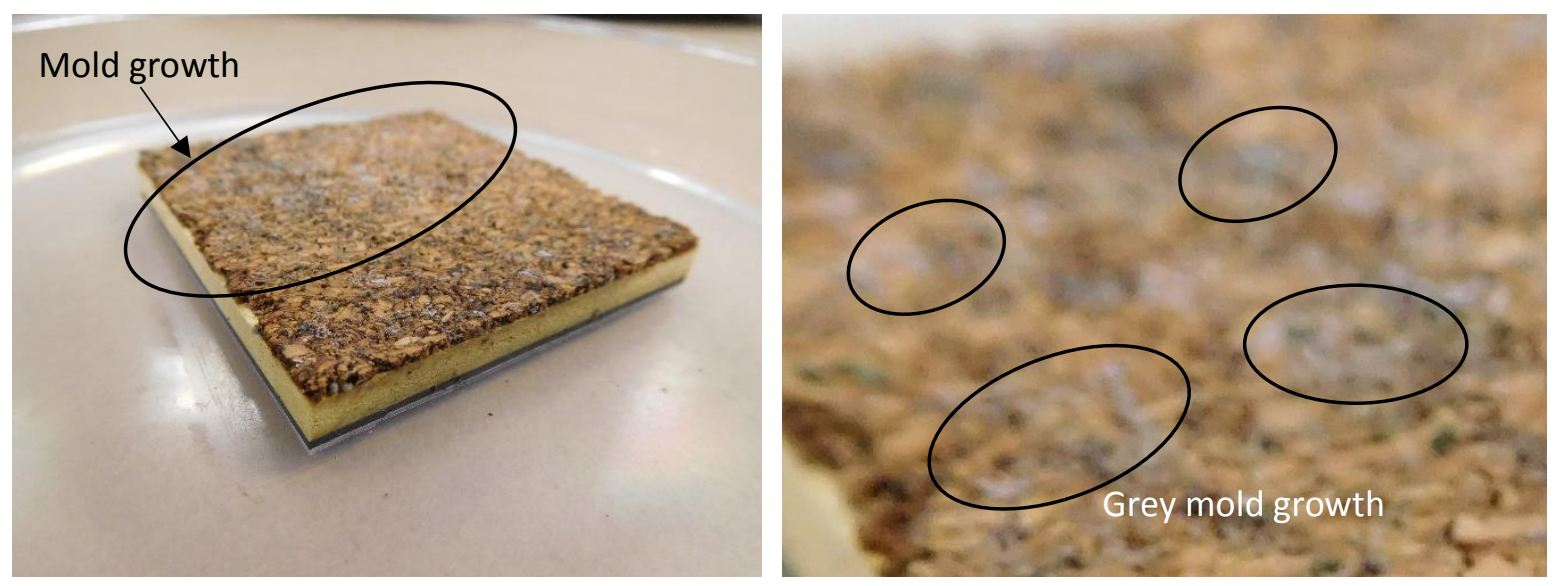

Figure 6.2.3.4: Mold growth on S17
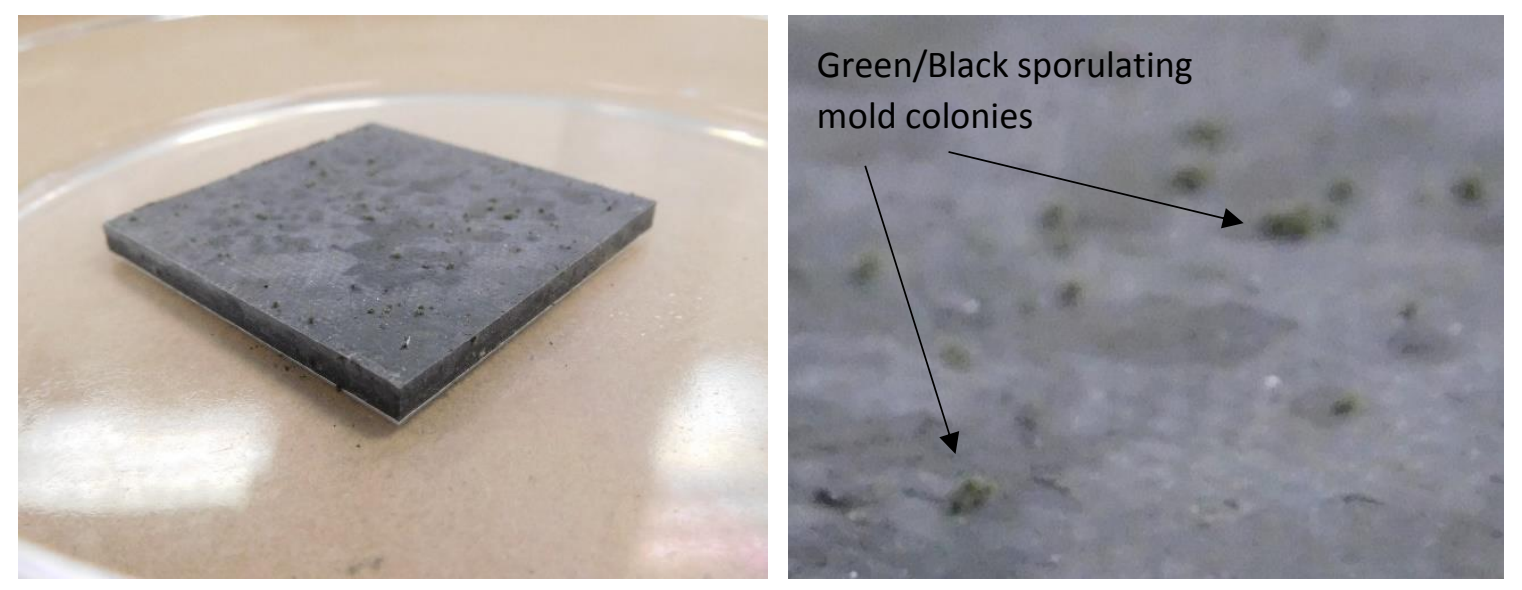

Figure 6.2.3.5: Mold growth on S22

\subsubsection{Sides}

Twenty-two of the 25 PBM products exhibited mold growth on the side surfaces where the core layer was exposed. On the side surfaces, growth was immediate, profuse, and sporulating with the inoculum germinating more quickly and more profusely than observed on the top and bottom surfaces. Again, differing rates of growth were observed on products with different materials. For those products with multiple layers, growth may have started in one layer, and if so, later spread to all layers.

As previously discussed in Section 3.2, inhalation of the spores (by humans or pets) can result in the development of allergies and other health problems. From the results of this study, mold growth in the sides or core layers presented the greatest concern; the growth was both profuse and had 
direct access to indoor air via the seams of the flooring. As already discussed, this is further exacerbated in that walking on the flooring can contaminate indoor air through movement of the flooring, potentially driving the spores into the living space.

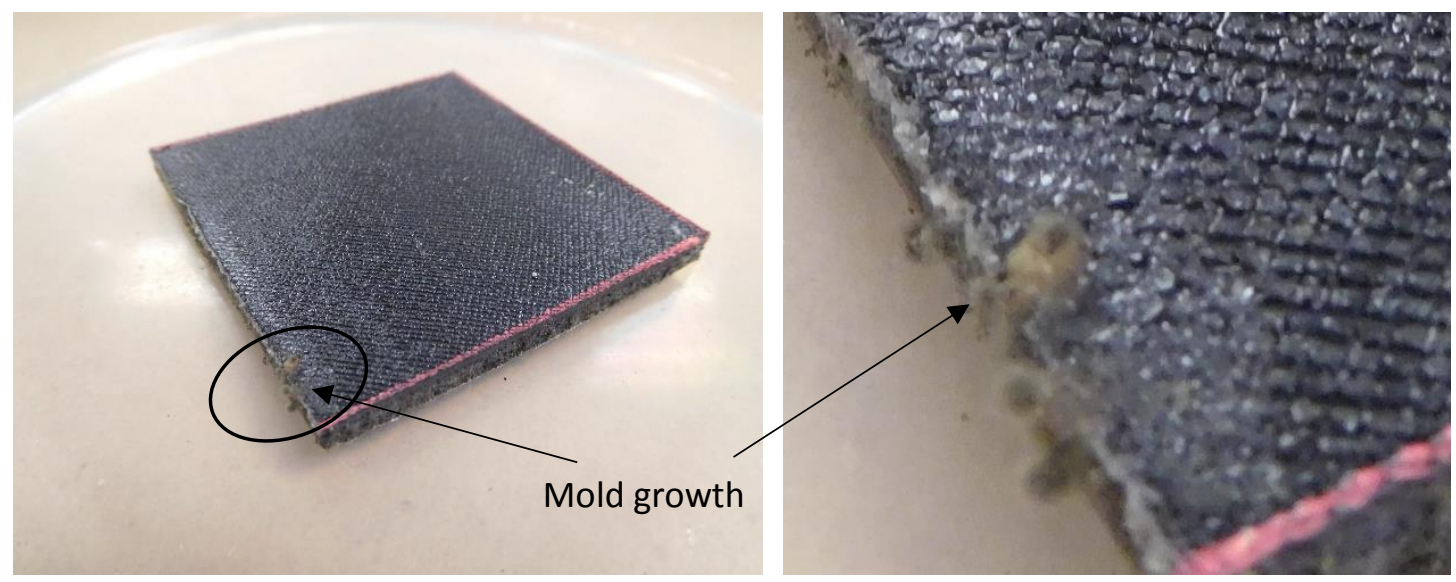

Figure 6.2.4.1: Mold growth on $\mathrm{S} 1$
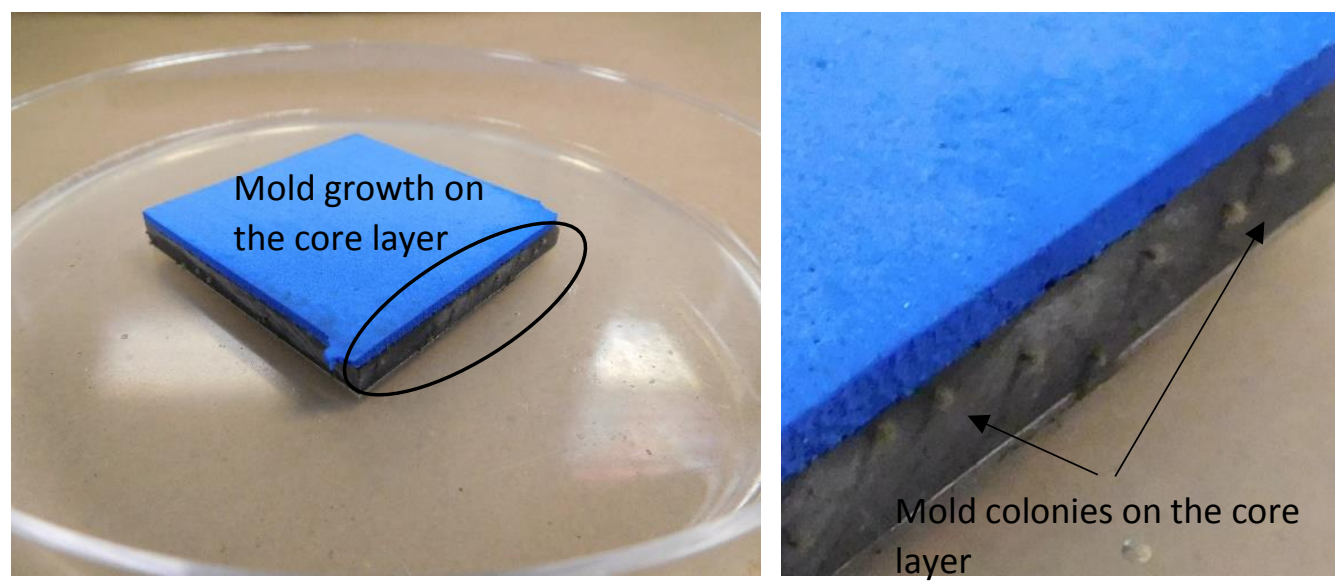

Figure 6.2.4.2: Mold growth on S3 

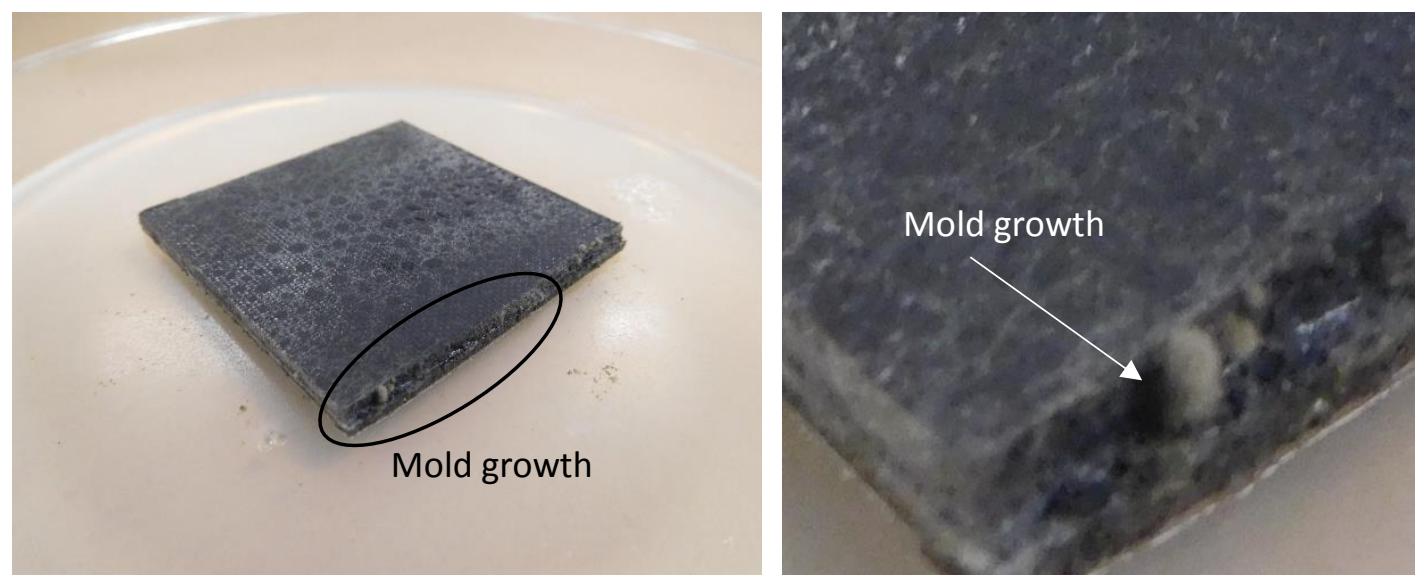

Figure 6.2.4.3: Mold growth on S5
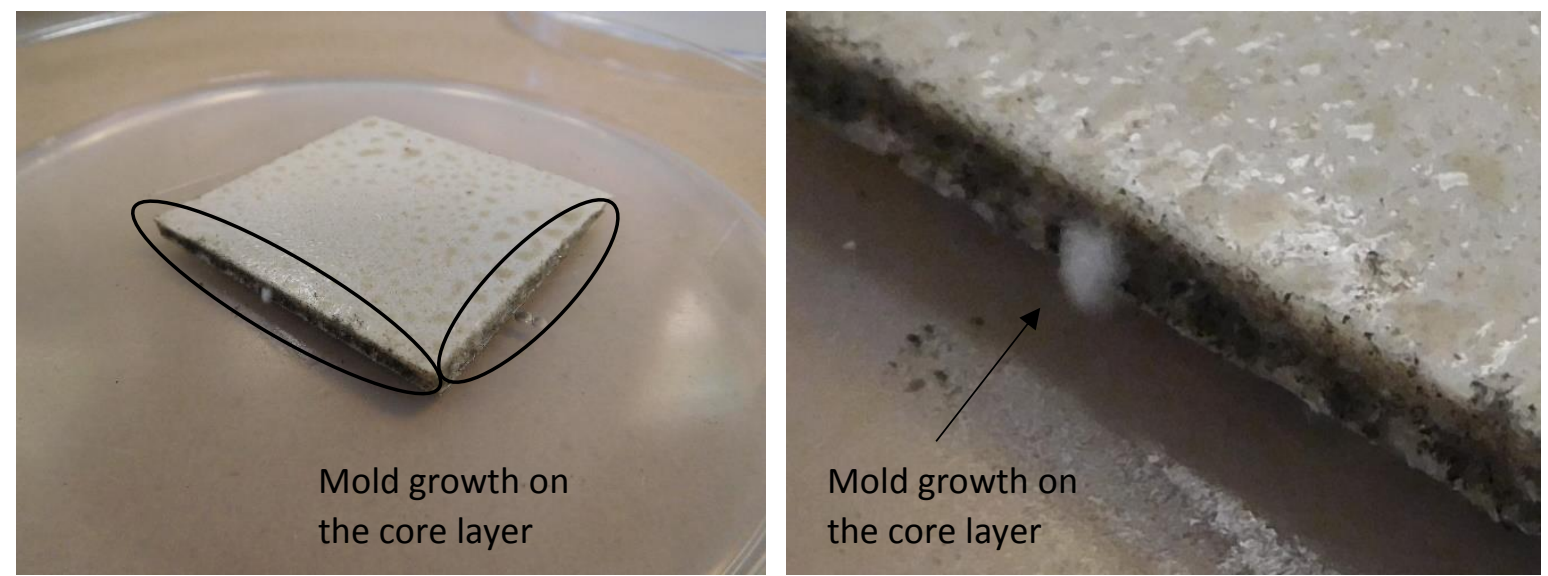

Figure 6.2.4.4: Mold growth on S7

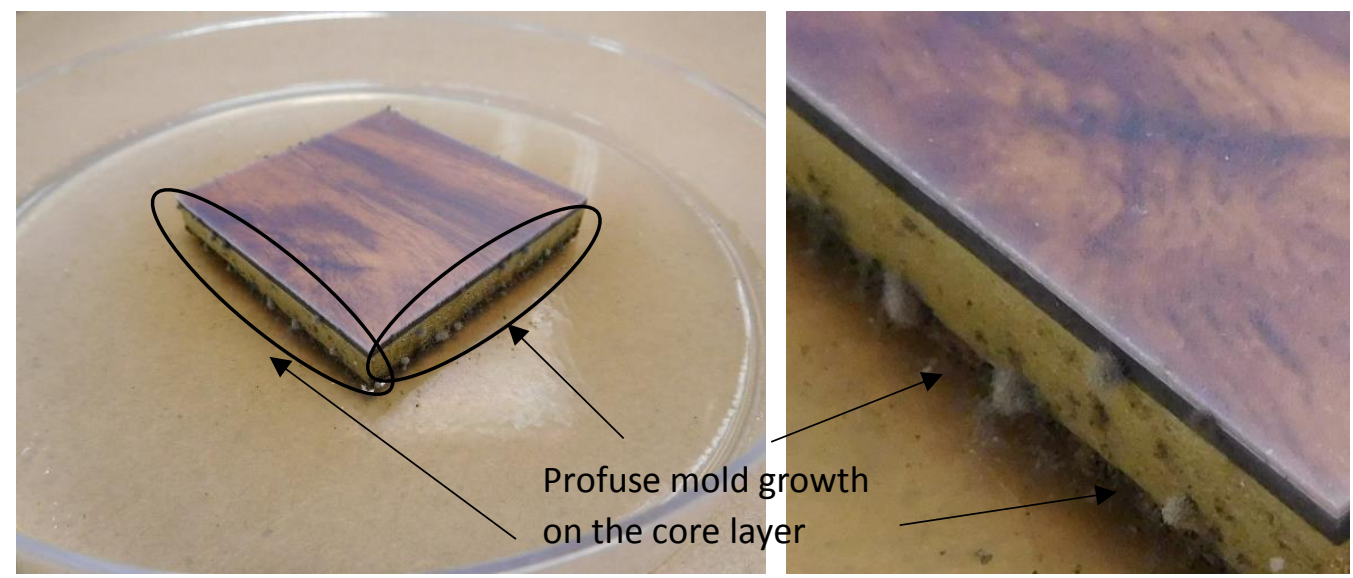

Figure 6.2.4.5: Mold growth on S8 

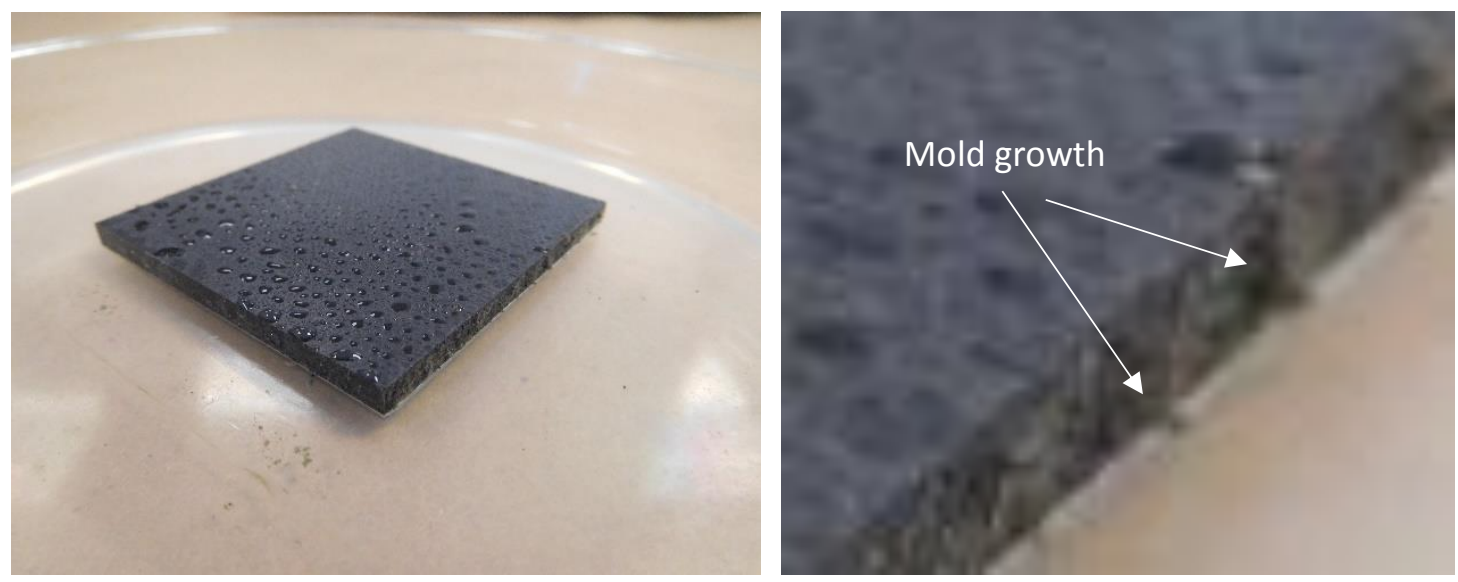

Figure 6.2.4.6: Mold growth on S11
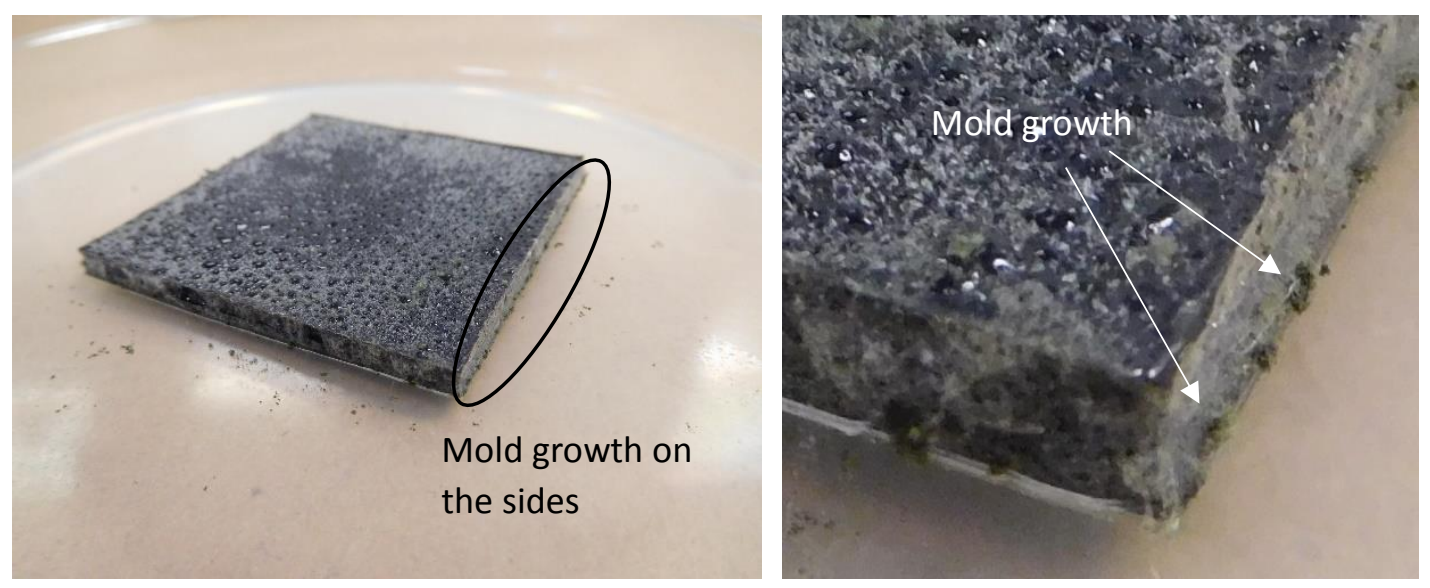

Figure 6.2.4.7: Mold growth on S13
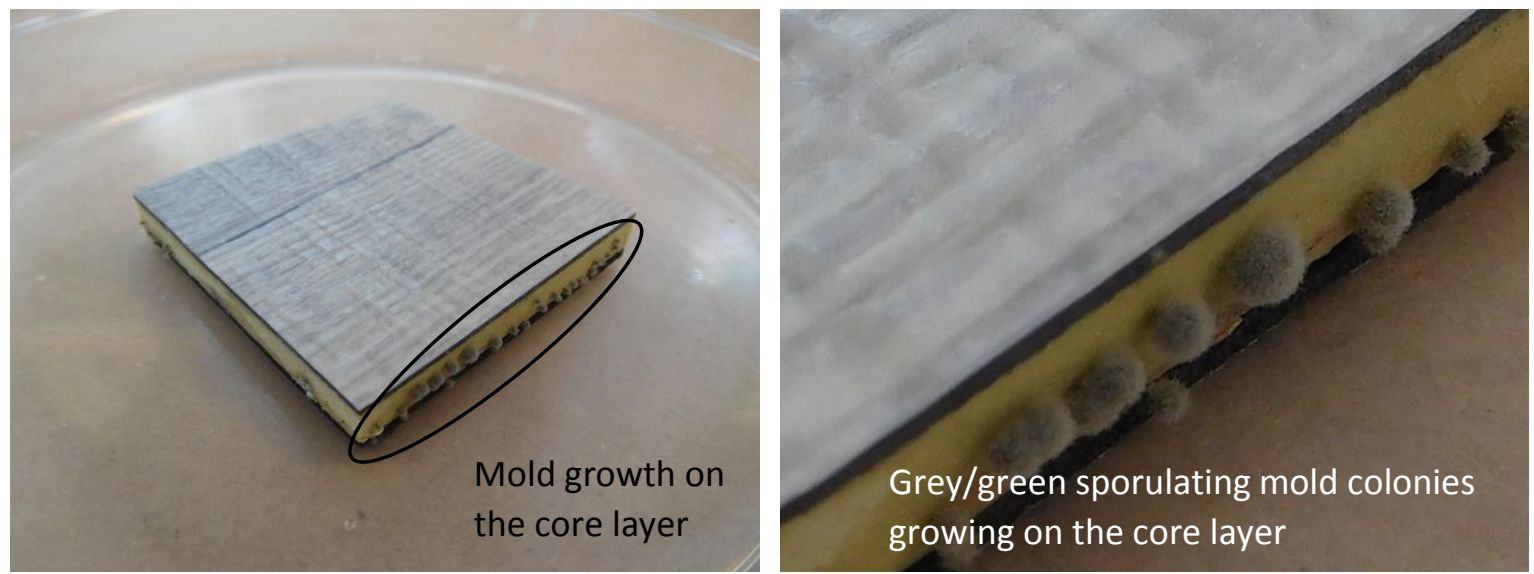

Figure 6.2.4.8: Mold growth on S15 


\subsection{Ceramic tile}

Ceramic tile products did not exhibit mold growth on any of the surfaces tested.
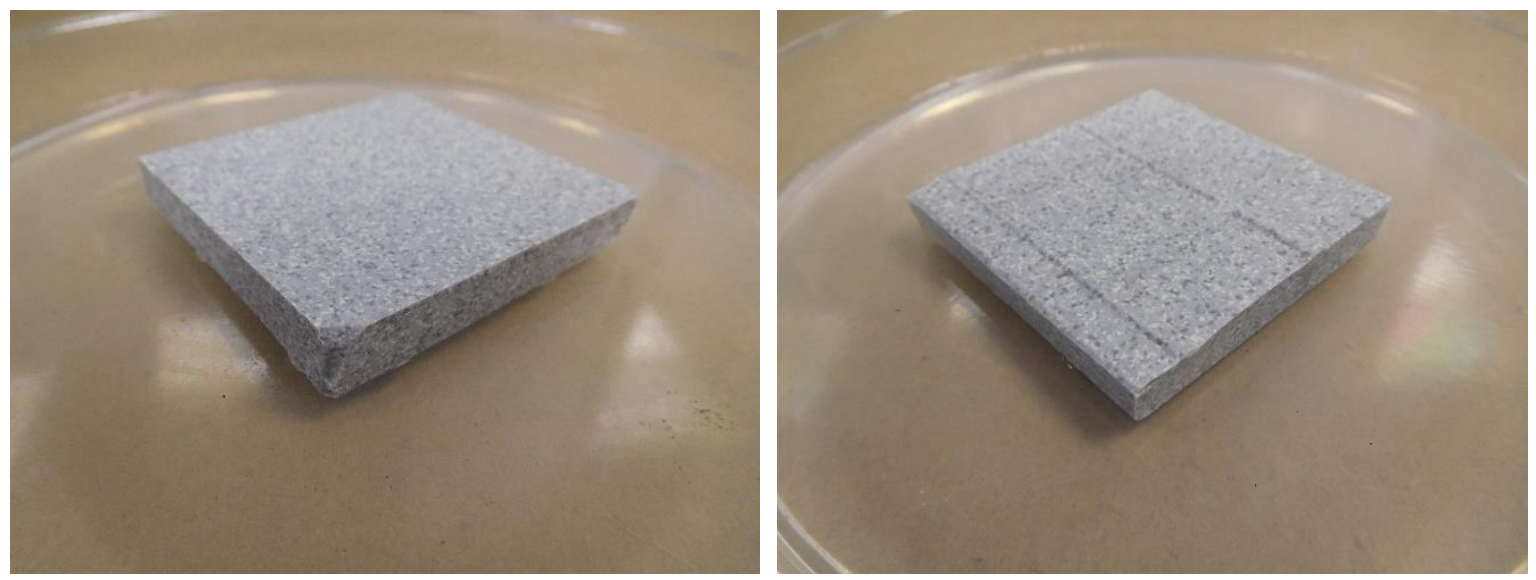

Figure 6.3.1: Mold growth on ceramic tile (porcelain) - top and bottom surfaces 


\subsection{Conclusions}

Testing showed that all 25 PBM flooring products, all of which were advertised or claimed to be waterproof, water resistant, or depicted being used in areas where flooring gets wet, supported mold growth. Of these, 22 out of 25 products excluded damage from mold or excessive moisture in their warranty statements. Mold growth rates from 1 to 4, per the ASTM G21-96 (2015) rating index, were observed, where top surfaces were found to support the least mold growth and the sides were found to support the most mold growth. As discussed in Section 6.2.4, mold growth on the sides is especially problematic as it can be profuse and sporulating and can directly contaminate indoor air. Growth was also observed on the bottom of more than half of the specimens tested, with such hidden mold able to grow without detection until levels of growth become obvious. Given the possibility of material degradation and potentially serious health consequences from mold spores, MVOC's, mycotoxins, and other environmental toxicants resulting from mold growth as detailed in Section 3.2, and the likelihood of damp and favorable conditions for mold growth as detailed in Section 3.3, a dry use-only caution, and/or warning regarding potential for mold growth, should be considered for products that perform similarly to those tested in this report. This is especially relevant given the exclusion for mold damage in many warranties. 